\title{
WSSV infection activates STAT in shrimp
}

\author{
Wei Yu Chen ${ }^{a}$, Kun Chin $\mathrm{Ho}^{a}$, Jiann Horng Leu ${ }^{a}$, Kuan Fu Liu ${ }^{a, b}$, \\ Han Ching Wang ${ }^{a}$, Guang Hsiung Kou ${ }^{a, *}$, Chu Fang Lo ${ }^{a, *}$
}

\author{
${ }^{a}$ Institute of Zoology, National Taiwan University, Taipei 106, Taiwan, ROC \\ ${ }^{\mathrm{b}}$ Tungkang Marine Laboratory, Taiwan Fisheries Research Institute, Tungkang, Taiwan, ROC
}

Received 3 September 2007; received in revised form 4 March 2008; accepted 5 March 2008 Available online 7 April 2008

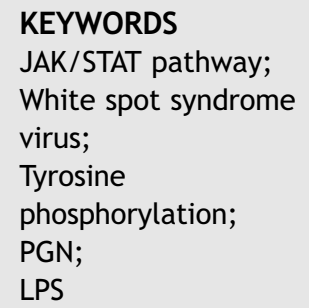

Abbreviations: STAT, signal transducers and activators of transcription; WSSV, White Spot Syndrome Virus; LPS, lipopolysaccharide.

*Corresponding authors. Tel.: +886223633562; fax: +886223638179 .

E-mail address: gracelow@ntu.edu.tw (C.F. Lo).

\begin{abstract}
Summary
Although the JAK/STAT signaling pathway is usually involved in antiviral defense, a recent study suggested that STAT might be annexed by WSSV (white spot syndrome virus) to enhance the expression of a viral immediate early gene in infected shrimps. In the present study, we clone and report the first full-length cDNA sequence for a crustacean STAT from Penaeus monodon. Alignment and comparison with the deduced amino acid sequences of other STATs identified several important conserved residues and functional domains, including the DNA binding domain, $\mathrm{SH} 2$ domain and $\mathrm{C}$-terminal transactivation domain. Based on these conserved sequences, a phylogenetic analysis suggested that shrimp STAT belongs to the ancient STAT family, while the presence of the functional domains suggested that shrimp STAT might share similar functions and regulating mechanisms with the wellknown STATs isolated from model organisms. Real-time PCR showed a decreased transcription level of shrimp STAT after WSSV infection, but a Western blot analysis using anti-phosphorylated STAT antibody showed an increased level of phosphorylated (activated) STAT in the lymphoid organ of shrimp after WSSV infection. We further show that a primary culture of lymphoid organ cells from WSSV-infected shrimp resulted in activated STAT being translocated from the cytoplasm to the nucleus. This report provides experimental evidence that shrimp STAT is activated in response to WSSV infection. Our results support an earlier finding that WSSV does not disrupt JAK/STAT pathway, but on the contrary benefits from STAT activation in the shrimp host.
\end{abstract}

(c) 2008 Elsevier Ltd. All rights reserved.

\section{Introduction}

The importance of the JAK/STAT signaling pathway in antiviral immunity has been addressed extensively in mammals [1], and increasing evidence has suggested that this pathway also plays a role in invertebrate organisms during virus infection [2-4]. Activation of the JAK/STAT 
pathway results in the phosphorylation of STATs at a single tyrosine residue near the carboxyl terminus. The tyrosinephosphorylated STATs then dimerize and translocate to the nucleus, where they transcriptionally activate appropriate genes to mediate various responses, including cell growth, cell differentiation and immune responses [5].

The immune responses mediated by the JAK/STAT pathway have been widely studied in model organisms. Genetic knockout studies of mice suggested that the mammalian JAK/STAT signaling pathway is predominant in controlling immune responses, especially the antiviral response [6]. In insects, the first evidence of the JAK/STAT pathway being involved in immune responses was in the mosquito Anopheles gambiae, whereas in mammals, AgSTAT translocated into the nucleus of the fat body cell upon bacterial infection [7]. When Drosophila is challenged by bacteria, the JAK/STAT pathway activates at least two gene families, TEP and TOT, that are involved in innate immunity $[8,9]$. The transcriptional profile of Drosophila C Virus-infected Drosophila further suggests that the JAK/STAT pathway might also respond to viral infection [10]. Taken together, these data suggest that in addition to the Toll and Imd pathways, the JAK/STAT pathway could be a third evolutionarily conserved pathway that supports innate immunity in insects. Because the JAK/STAT pathway plays a significant antiviral role, it follows that this pathway might be targeted by a virus that is attempting to evade the host's immune responses; and in fact, several viruses have been shown to counter their hosts' antiviral mechanisms by inhibiting the JAK/STAT signaling pathway. For example, the $\mathrm{V}$ protein of simian virus targets its host's STAT1 for degradation [11], while the human cytomegalovirus targets JAK1 for degradation [12]. Infection with the varicella-zoster virus inhibits the expression of both STAT1 and JAK2 [13]. Hepatitis $C$ virus also inhibits host immunity by disrupting the crosstalk between the MAPK and JAK/STAT pathways [14].

WSSV also targets STAT, but instead of inhibiting or disrupting its activity, WSSV exploits the host STAT by using it to bind to the promoter region of the WSSV immediate early gene ie1 and thus enhance ie1 transcription [2]. To better understand how the JAK/STAT pathway generally responds to pathogens in shrimp, in the present study, we first cloned and characterized the full-length cDNA sequence of shrimp STAT from Penaeus monodon. Next, real-time RTPCR was used to investigate whether the transcription level of STAT was changed after Litopenaeus vannamei were challenged with WSSV and the immune stimulants LPS and PGN (lipopolysacharide and peptidoglycan). A previous study had used EMSA to show that WSSV infection led to increased levels of activated STAT, so when our RT-PCR results showed that STAT transcription was reduced after challenge with WSSV, we used two other more direct methods (a phosphorylation status analysis and an immunostaining assay) to reconfirm the activation status of STAT in lymphoid organ cells of WSSV-infected shrimp.

\section{Materials and methods}

\section{Cloning of full-length shrimp STAT cDNA}

Specimens of adult $P$. monodon (30-40 g) were collected from a culture pond at the Biotechnology Division of the
Fisheries Research Institute in southern Taiwan and kept in a $70 \mathrm{l}$ tank maintained at $25-28^{\circ} \mathrm{C}$. Pleopods were excised from two or three of these shrimp, immediately frozen and stored in liquid nitrogen until used. These frozen pleopods were then homogenized in $6 \mathrm{ml}$ Trizol reagent (Invitrogen, USA) and subjected to RNA extraction. An aliquot of $10 \mu \mathrm{g}$ of RNA was treated with $200 \mathrm{U}$ of RNase-free DNase I at $37^{\circ} \mathrm{C}$ for $30 \mathrm{~min}$ and then extracted with phenol-chloroform. The DNase-treated total RNA was denatured by heating at $85^{\circ} \mathrm{C}$ for $10 \mathrm{~min}$ in $10 \mu \mathrm{l}$ DEPC-water containing $100 \mathrm{pmol}$ oligo(dT) anchor primer. The first-strand cDNA was synthesized by Superscriptll reverse transcriptase (Invitrogen, USA) at $37^{\circ} \mathrm{C}$ for $1 \mathrm{~h}$, followed by heating at $95^{\circ} \mathrm{C}$ for $5 \mathrm{~min}$ to stop the reaction. A partial STAT CDNA fragment was then cloned using the forward and reverse VNM-STAT primers $\left(5^{\prime}\right.$ GAGTCAGTGATGGATGAGAAA-3' and 5'-GTCGGAGAAACGGAGCAAGAA-3'; designed from a $L$. vannamei EST clone whose $5^{\prime}$ end had a high homology to insect STATs). The resulting PCR product was subcloned into PGEM-T easy vector (Promega, USA) and sequenced.

The $5^{\prime} / 3^{\prime}$ regions of the shrimp STAT transcript were determined by $5^{\prime} / 3^{\prime}$ RACE using a commercial 5'/3'-RACE kit (Roche, Germany). For $5^{\prime}$ RACE, the appropriate genespecific primer, stat-5'RACE-rp5 (5'-CACTAATGATTGAGACCCGCAC- $3^{\prime}$ ), was used for CDNA synthesis. Before being subjected to PCR, a polyA sequence was added to the CDNA products with terminal transferase (TdT) in the presence of dATP. The first step of the PCR for shrimp STAT was performed using the gene-specific primer stat-5'RACE-rp6 (5'-CTTTGAATGTGGGAAAGGTGAGC-3') and an oligo (dT) anchor primer (5'-GACCACGCGTATCGATGTCGACTTTTTTTTTTTTTTTTV-3'). This was followed by nested PCR with the gene-specific primer stat-5'RACE-rp7 (5'-TCATTTGCCGTTTCCCGTGTAC- $\left.3^{\prime}\right)$ and the anchor primer (5'-GACCACGCGTATCGATGTCGAC- $\left.3^{\prime}\right)$. The CDNA synthesized from the oligo(dT) anchor primer was subjected to $3^{\prime}$ RACE PCR. Similarly, $3^{\prime}$ RACE was performed with two rounds of PCR, first with the gene-specific primer stat-3'RACE-fp (5'-GTGGAAGGATGGCTCCATCATG-3') and an oligo (dT) anchor primer and then with gene-specific primer stat-3'RACE-fp1 (5'-ATGCTTAAGAATTCCAAGTCAGG-3') and an anchor primer. The resulting 5'/3' RACE PCR products were cloned into PGEM-T vector and sequenced.

\section{Shrimp STAT sequence analysis and phylogenetic analysis}

The complete coding sequence of shrimp STAT was compared with the GenBank database using the program BlastX, and the cDNA sequence were deposited in the NCBI database (AY327491). Ten STAT amino acid sequences were retrieved from GenBank, and were used for sequence alignment and phylogenetic analysis. Multiple sequence alignment was done using the program ClustalX and edited with Genedoc software. Phylogenetic analysis was based on the sequence of the STATs' conserved central region from the DNA binding domain to the $\mathrm{SH} 2$ domain (aa340-aa692 in shrimp STAT), and was performed with Mega4.0 software using the Neighbor-Joining algorithm. One thousand bootstrap replicates were generated to test the robustness of the trees. 


\section{Quantitative real-time PCR analysis of shrimp STAT after challenge with immune stimulants}

For this analysis, the more readily available specific pathogen free white shrimp, L. vannamei, were used instead of $P$. monodon. Live shrimps with an average body-weight of $1 \mathrm{~g}$ were cultured in a Marine Research Station (Institute of Cellular and Organismic Biology, Academia Sinica) located in I-lan, Taiwan. Eight days before the experiment, the shrimps were moved to large tanks ( $500 \mathrm{l}$ ) and kept at $27^{\circ} \mathrm{C}$, and 1 day before the experiment, the shrimps were further transferred into small tanks ( $40 \mathrm{l}$ ) for acclimation. The shrimps were then challenged by injection with $50 \mu \mathrm{l}$ of immune stimulant (WSSV, LPS, PGN or PBS vehicle only) into the dorsal part of the third abdominal segment. The WSSV inoculant was prepared from WSSV T-1 isolate (GenBank accession number: AF440570) as described previously [15]. The PGN (Cat no. 69554, Fluka, from Bacillus subtilis) and LPS (L-2630, Sigma, from Escherichia coli 0111:B4) stimulants were dissolved in PBS to a concentration of 0.02 and $0.2 \mu \mathrm{g} / \mu \mathrm{l}$, respectively. The PBS vehicle was used as a control. At 6 and $24 \mathrm{~h}$ post injection (hpi), the cephalothoraces were taken from four to six shrimps and stored in liquid nitrogen. Total RNA was extracted and cDNA was synthesized as described above (in Section "Cloning of full-length shrimp STAT CDNA"). The CDNAs were then subjected to real-time PCR analysis in a $20 \mu \mathrm{l}$ reaction mixture containing $10 \mu \mathrm{l}$ of SYBR GREEN PCR Master Mix reagent (Applied Biosystems), $2 \mu$ lof cDNA template, $4 \mu \mathrm{l}$ of $\mathrm{ddH}_{2} \mathrm{O}$ and $2 \mu \mathrm{l}(3 \mu \mathrm{M})$ of forward and reverse primer either for STAT (STAT-new-390F: 5'-AGCCCCTGTCTGAGCGAAA-3', STAT-new-461R: 5'-GGTGTTCTCTTGTGACCTT(ATCA-3') or else for housekeeping control gene EF-1 $\alpha$ (P2547: 5'-TGCTCTGGACAACATCGAGC-3') and P2548: 5'-CGGGCACTGTTCCAATACCT-3'). The analysis was performed using a 7500 real-time PCR system (Applied Biosystems), and the PCR reaction conditions were as follows: $50^{\circ} \mathrm{C}$ for $2 \mathrm{~min}$ and $95^{\circ} \mathrm{C}$ for $10 \mathrm{~min}$, followed by 40 cycles of $95^{\circ} \mathrm{C}$ for $15 \mathrm{~s}$ and $60^{\circ} \mathrm{C}$ for $1 \mathrm{~min}$, with one dissociation stage at $95^{\circ} \mathrm{C}$ for $15 \mathrm{~s}, 60^{\circ} \mathrm{C}$ for $30 \mathrm{~s}$, and $95^{\circ} \mathrm{C}$ for $15 \mathrm{~s}$. The dissociation curve of each PCR product was a single peak. The PCR reaction was repeated three times for each sample. The $\Delta \Delta \mathrm{Ct}$ method was used to monitor the transcription level of the shrimp STAT target gene [16]. The $\mathrm{Ct}$ values of the amplified target gene $\left(\mathrm{Ct}_{\text {stat }}\right)$ and the internal control gene $\left(\mathrm{Ct}_{\mathrm{EF}-1 \alpha}\right)$ in each sample were computed by the SDS program using default parameters. $\Delta \mathrm{Ct}$ values were then calculated by subtracting $\mathrm{Ct}_{\mathrm{EF}-1 \alpha}$ from $\mathrm{Ct}_{\text {stat }}$. To normalize the data, $\Delta \mathrm{Ct}$ for each tested sample was subtracted from the average $\Delta \mathrm{Ct}$ of the calibrator (i.e. PBS-injected shrimp) to produce a value called $\Delta \Delta \mathrm{Ct}$. The change in transcription level of each sample relative to the transcription level of the calibrator was then expressed as $2^{-\Delta \Delta C t}$. The data obtained from this real-time PCR were subjected to a $T$-test where $p$-values below 0.05 were considered to be significant.

\section{Recognition of shrimp STAT by anti-phosphorylated human STAT5a antibody}

The polyclonal rabbit anti-phosphorylated human STAT5a antibody $\alpha-{ }_{p}$ STAT5a (Abcam, UK) was raised against synthetic phosphopeptide derived from human STAT5a around the phosphorylation site of tyrosine 694. In this experiment, the ability of $\alpha_{-p}$ STAT5a to recognize recombinant PmSTAT was compared to that of a rabbit anti-shrimp STAT antibody, $\alpha$-PmSTAT, that was generated in a previous study [2].

To express rPmSTAT, S. frugiperda (Lepidoptera: Noctuidae) SF-9 insect cells that had been maintained at $27^{\circ} \mathrm{C}$ in Sf-900 II SFM medium (Invitrogen) supplemented without fetal bovine serum were seeded in six-well plates $\left(0.5 \times 10^{6} \mathrm{cells} /\right.$ well $)$. Using an Effecten Reagent kit (Qiagen, Germany), the cells were then transfected with either $1 \mu \mathrm{g}$ PmSTAT expression plasmid, pDhsp/PmSTAT/V5His or the control plasmid, pDhsp/V5-His (with no PmSTAT insertion) [2]. After transfection for $16-18 \mathrm{~h}$, the cells were heat shocked in a $42{ }^{\circ} \mathrm{C}$ water bath for $30 \mathrm{~min}$ and then returned to $27^{\circ} \mathrm{C}$. At 5-6 h after heat shock, the cells were lysed with SDS sample buffer and cell lysates were subjected to separation in $12.5 \%$ SDS-PAGE and transferred onto PVDF membrane (Perkin-Elmer, USA). The membranes were incubated in blocking buffer (5\% skim milk in TBST solution, $50 \mathrm{mM}$ Tris, $500 \mathrm{mM} \mathrm{NaCl}$ and $0.5 \%$ Tween 20 at pH 7.5) at $4{ }^{\circ} \mathrm{C}$ overnight. After blocking, the membranes were reacted for $1 \mathrm{~h}$ with either $\alpha_{-\mathrm{p}}$ STAT5a (1:2000 dilution in blocking buffer), or with $\alpha$-PmSTAT (1:5000 dilutions in blocking buffer). The membranes were washed four times in TBST solution, and then incubated with horseradish peroxidase conjugated secondary antibody (1:5000 in blocking buffer). The washing step was repeated and the proteins were visualized using a chemiluminescence reagent (PerkinElmer, USA).

\section{Western blot analysis of phosphorylated shrimp STAT in the nuclear fraction of lymphoid organ (LO) cells}

In this analysis, adult $P$. monodon were challenged by injection with $100 \mu \mathrm{l}$ of the WSSV T-1 inoculum described above into the dorsal part of the third abdominal segment. At 4 or $24 \mathrm{hpi}$, the LO of the experimental shrimps were excised and immediately subjected to cytoplasmic and nuclear separation using a commercial kit (NE-PER; Pierce, USA) according to the manufacturer's instructions. The protein concentration in the samples was determined by using the Bio-Rad protein assay kit (BIO-RAD, USA). Extracts ( $\sim 15 \mu$ g perwell) were subjected to separation in $10 \%$ SDS-PAGE gel in duplicate under identical conditions; one duplicate was stained with coomassie brilliant blue to confirm that the samples was equally loaded, and the other was transferred onto PVDF membrane (Perkin-Elmer, USA) for Western blot analysis. The membranes were incubated in blocking buffer ( $5 \%$ skim milk in TBST solution) at $4{ }^{\circ} \mathrm{C}$ overnight. After blocking, the membranes were reacted for $1 \mathrm{~h}$ with the polyclonal antibody, $\alpha{ }_{-}$STAT5a (Abcam, UK; 1:2500 dilution in blocking buffer). The membranes were washed four times in TBST solution $(50 \mathrm{mM}$ Tris, $500 \mathrm{mM} \mathrm{NaCl}$ and $0.5 \%$ Tween 20 at $\mathrm{pH} 7.5$ ), and then incubated with horseradish peroxidase conjugated secondary antibody (1:5000 in blocking buffer). The washing step was repeated and the proteins were visualized using a chemiluminescence reagent (Perkin-Elmer, USA). 


\section{Immunofluorescence detection of STAT in primary cultures of LO cells collected from uninfected and WSSV-infected $p$. monodon}

Primary cultures of lymphoid organ (LO) cells were prepared as described previously with slight modifications [17]. Briefly, mock and WSSV-infected (12 hpi) P. monodon (with an average bodyweight of $50 \mathrm{~g}$ ) were anesthetized on ice and surface-sterilized with $70 \%$ alcohol. Their LOs were then excised, washed in culture medium $(2 \times$ Leibovitz's 15 medium, $10 \%$ fetal bovine serum, $0.1 \%$ glucose, $1000 \mathrm{U} / \mathrm{ml}$ penicillin, $1000 \mu \mathrm{g} / \mathrm{ml}$ streptomycin, $0.25 \mu \mathrm{g} / \mathrm{ml}$ Fungizone), and transferred into a fresh $1.5 \mathrm{ml}$ tube. The LOs were subsequently minced into small pieces $\left(2-3 \mathrm{~mm}^{3}\right)$, dispersed by pipetting gently and then seeded ( $50 \mu$ lperwell) into a cover glass in a 24-well plate (Nalge Nunc International, Denmark). After incubation for $12 \mathrm{~h}$ at $27^{\circ} \mathrm{C}$ to allow the cells to settle on the cover glass, the medium was removed and the cells were washed twice with PBS. The cells were fixed in $4 \%$ paraformaldehyde in PBS, briefly exposed to acetone at $4{ }^{\circ} \mathrm{C}$, and then washed thoroughly with PBS. After blocking overnight in 3\% BSA in PBS, the cells were reacted first with either rabbit anti-shrimp STAT serum that was generated in a previous study [2] (1:250 in blocking buffer), or else with rabbit pre-immunized serum, which was used as a non-specific binding control for STAT. After washing with PBST $(0.2 \%$ Tween 20 in PBS), the cells were then reacted with FITC dye-conjugated donkey anti-rabbit IgG antibody $(1: 250$ in blocking buffer; the antibody was from Jackson Immuno Research [West Grove, PA]) for $3 \mathrm{~h}$ at RT. After counterstaining with DAPI, the glass was wet mounted with antifading polyvinyl alcohol medium with DABCO (Fluka, USA). Fluorescent signals were observed with a confocal microscope fitted with a UV microscopy apparatus.

\section{Results}

\section{Characterization of shrimp STAT}

Altogether, the full-length cDNA of shrimp STAT (Accession number: AY327491) contains a 2235 nucleotide coding region that encodes 744 amino acid residues with a predicted molecular weight of $88.4 \mathrm{kDa}$. The cDNA sequence of shrimp STAT suggested that the transcription initiation site is 134 nucleotides upstream of the start codon, ATG, and that the polyA signal sequence, AATAAA, is located between 49 and 54 nucleotides downstream of the stop codon. Using multiple sequence alignment, several functional domains, including the DNA binding domain (aa340-aa505), SH2 domain (aa599-aa692) and C-terminal transactivation domain (aa693-aa773), were identified in shrimp STAT (Figure 1). Several conserved amino acid residues that provide important regulation mechanisms in known STATs were also found in shrimp STAT (i.e. C-terminal phosphorylation sites at Y706 and S725, and methylation site at R31).

To investigate the evolutionary relatedness between shrimp STAT and other STATs, the conserved central region from the DNA binding domain to the $\mathrm{SH} 2$ domain (aa340-aa692) was subjected to phylogenetic analysis. The resulting identity matrix (Figure 2A) and dendrogram (Figure 2B) suggest that shrimp STAT is relatively close to the insect STATs (Spodoptera frugiperda STAT, Anopheles gambiae STAT, drosophila STAT) and to human STAT5a/5b and human STAT6.

\section{Transcription level of shrimp STAT decreased after WSSV infection}

Real-time RT-PCR was used to test whether the transcription level of shrimp STAT was changed after challenge by WSSV and two bacterial immune stimulants, PGN and LPS. Data were expressed as $2^{-\Delta \Delta C t}$ and changes in the transcription levels of the shrimp STAT target gene relative to the PBSinjected control are shown in Figure 3. The transcription levels of shrimp STAT were decreased after challenge with either PGN or WSSV (Figure 3A). At $6 \mathrm{hpi}$, the decrease was only statistically significant in the PGN challenged group but at $24 \mathrm{hpi}$, statistically significant decreases were observed in both of the challenged groups. In a separate study using LPS as the stimulant, there was no statistically significant difference from the control group (Figure 3B).

\section{Anti-phosphorylated human STAT5a antibody recognized shrimp STAT}

To determine whether anti-phosphorylated human STAT5a antibody could recognize shrimp STAT, we transiently transfected SF-9 cells with a shrimp STAT gene under the control of a Drosophila heat shock protein 70 promoter. After heat shock at $16-18 \mathrm{~h}$ post transfection, the recombinant shrimp STAT was detected by both the anti-shrimp STAT serum and the anti-phosphorylated human STAT5a antibody (Figure 4, lanes 2 and 4). No recombinant PmSTAT signal was detected in the Sf9 cells transfected with control plasmid (Figure 4, lanes 1 and 3). We concluded that the antiphosphorylated human STAT5a antibody was successfully able to recognize shrimp STAT.

\section{Shrimp STAT was activated in response to WSSV infection}

To investigate whether the shrimp STAT was activated after WSSV infection, cytoplasmic and nuclear extracts of the LOs from non-infected and WSSV-infected shrimp were analyzed by Western blot using polyclonal anti-phosphorylated human STAT5a antibodies. Activated shrimp STAT was detected only in the nuclear fractions (Figure 5 ). Lane 1 shows the basal level of activated shrimp STAT in non-infected shrimp, and at $4 \mathrm{hpi}$ levels of activated STAT were approximately the same (Figure 5, lane 3 ). However, by $24 \mathrm{hpi}$, the levels of activated shrimp STAT were visibly increased (Figure 5, lane 5). Further evidence of the activation of shrimp STAT in vivo was provided by an immunostaining assay. In this assay, green fluorescence from the FITC-labeled shrimp STAT protein was visible in both the uninfected and WSSVinfected primary culture LO cells (Figure 6). However, in the uninfected cells, the fluorescence was absent in the nucleus (Figure 6A and B) whereas after WSSV infection ( $24 \mathrm{hpi}$ ) the signals were stronger and the protein was mostly located in the nucleus region (Figure 6C and D). Based on both the Western blot analysis and the immunostaining 

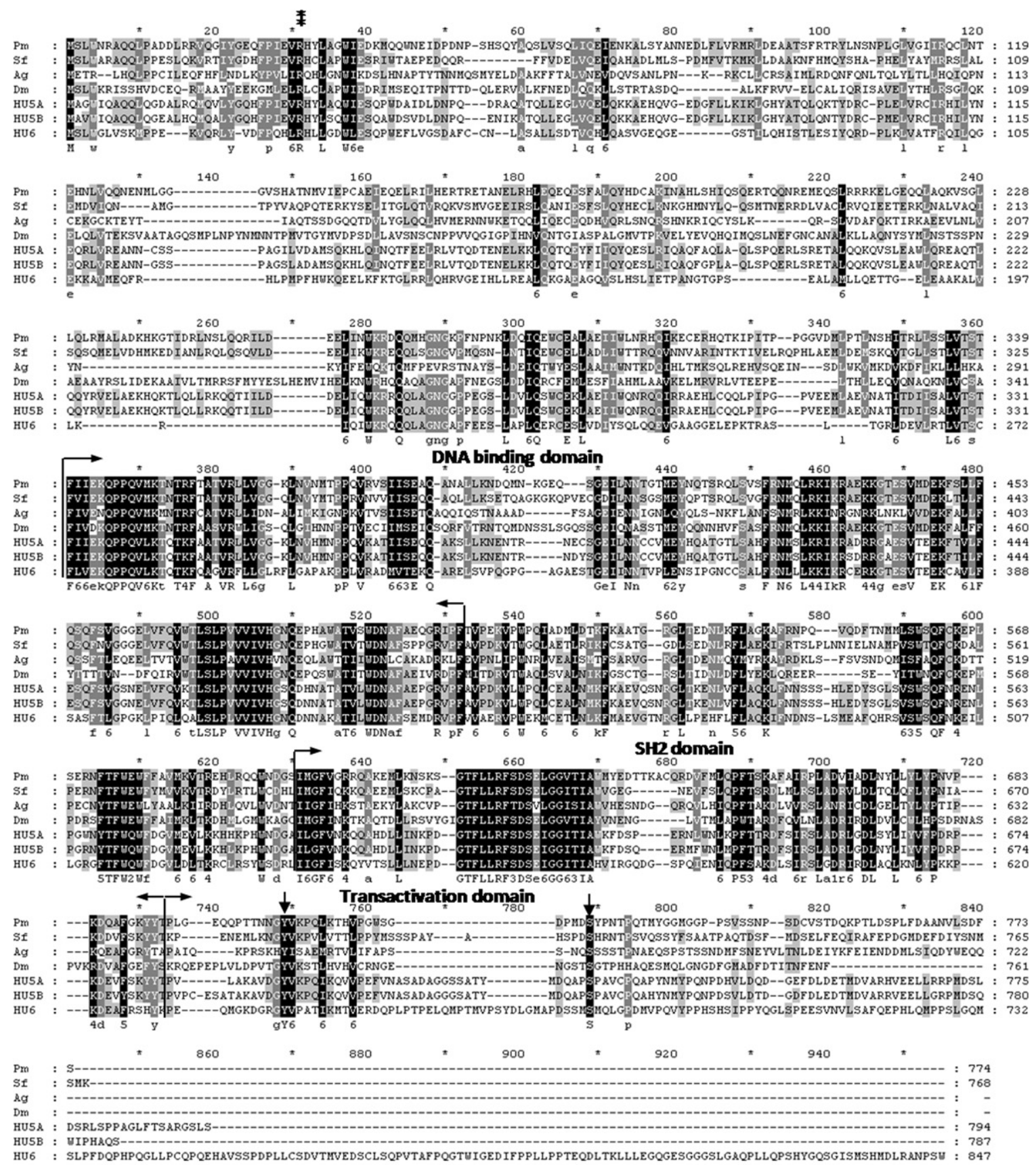

Figure 1 Multiple sequence alignment of the deduced amino acid sequence of the shrimp STAT gene with six ancient STAT family members. $\mathrm{Dm}=$ Drosophila melanogaster, $\mathrm{Ag}=$ Anopheles gambiae, $\mathrm{Sf}=$ Spodoptera frugiperda, $\mathrm{Pm}=$ Penaeus monodon, $\mathrm{Hu}=$ Human STAT (five other STATs that are not members of the ancient STAT family are not shown). Identified domains including the DNA binding domain (aa340-aa505), the SH2 domain (aa599-aa692) and C-terminal transactivation domain (aa693-aa773) are indicated with arrow brackets. Two conserved phosphorylated residues, tyrosine 706 and serine 725 , are indicated with vertical arrows, and the conserved methylated residue, arginine 31 , is indicated with a double asterisk.

assay, we conclude that challenge with WSSV leads to increased activation of shrimp STAT by tyrosine phosphorylation. We also note the appearance of double bands at $\sim 95 \mathrm{kDa}$ in Figure 5 (see especially lane 5 ). We hypothesize that these double bands may have resulted from a splicing event similar to those that have been reported in some mammalian STATs [18-20].

\section{Discussion}

The JAK/STAT signaling pathway is highly evolutionarily conserved and it is found in species from Dictyostelium discoideum to human. In the model organisms of mice, drosophila, mosquito and nematode, the JAK/STAT signaling pathway functions mainly in development and immune 


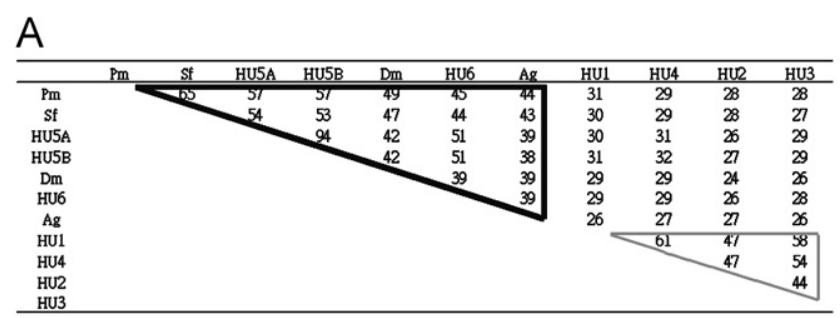

B

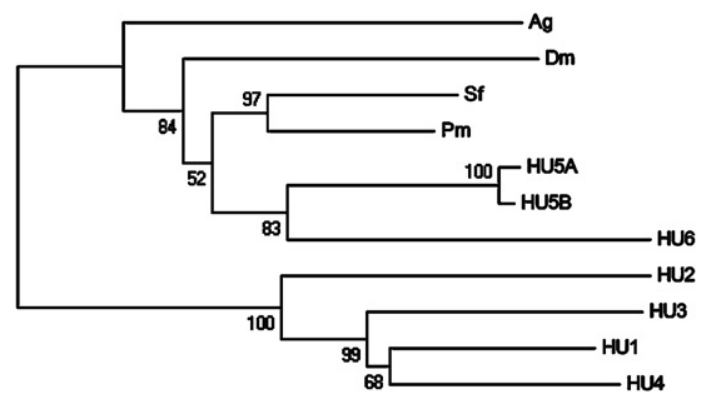

$\longmapsto 0.1$

Figure 2 Phylogenetic analysis (A) matrix of percentage identities of amino acids in the conserved central region for 11 members of the STAT family. GenBank accession numbers are as follows: Drosophila melanogaster $(\mathrm{Dm})=\mathrm{Q} 24151$, Anopheles gambiae $(\mathrm{Ag})=\mathrm{Q} 7 \mathrm{QDU} 4$, Spodoptera frugiperda $(\mathrm{Sf})=$ AAL37477, Penaeus monodon $(\mathrm{Pm})=$ AAQ94739, Human STAT1 $(\mathrm{Hu} 1)=$ AAH02704, STAT2 $(\mathrm{Hu2})=$ AAH51284, STAT3 $(\mathrm{Hu} 3)=\mathrm{P} 40763, \quad$ STAT4 $\quad(\mathrm{Hu} 4)=$ NP_003142, $\quad$ STAT5a $(\mathrm{Hu} 5 \mathrm{a})=$ NP_003143, STAT5b $(\mathrm{Hu} 5 \mathrm{~b})=$ NP_036580, STAT6 $($ Hu6 $)$ NP_003144. Comparisons between members of the ancient STAT family, including shrimp STAT, are delineated by larger bold triangle, while comparisons between other STATs are delineated by the smaller faint triangle. (B) Phylogenetic tree constructed by the Neighbor-Joining method and showing relatedness of the aligned conserved central region of 11 STATs. Robustness was tested by 1000 bootstrap replications. The indicated distance of 0.1 represents a $10 \%$ difference in the amino acid residues between compared sequences.

responses. Studies with gene knock-out mice suggest that the seven STATs found in both mice and humans are all associated with a specific role in host defense mechanisms. For example, the loss of STAT4, STAT5 $a / 5 b$ or STAT6 leads to deficient T-cell differentiation or proliferation, while the loss of STAT1, STAT2 or STAT3 function impairs interferon signaling [6]. However, in contrast to the role specificity of the mammalian STATs, many insect STATs have a wider spectrum of functions, with the same STAT being used in various responses. For example, there is only one STAT gene found in the Drosophila genome [21,22], and this drosophila STAT is involved in embryogenesis, hematopoiesis and anti-bacterial/viral mechanisms [23]. Similarly, AgSTAT, which is expressed by one of the only two annotated STATs in the genome of the mosquito $A$. gambiae [24,25], is also likely to have to fulfill several functions. By the same taken, STAT from the arthropod $P$. monodon probably also has multiple functions, although this had not been confirmed experimentally.

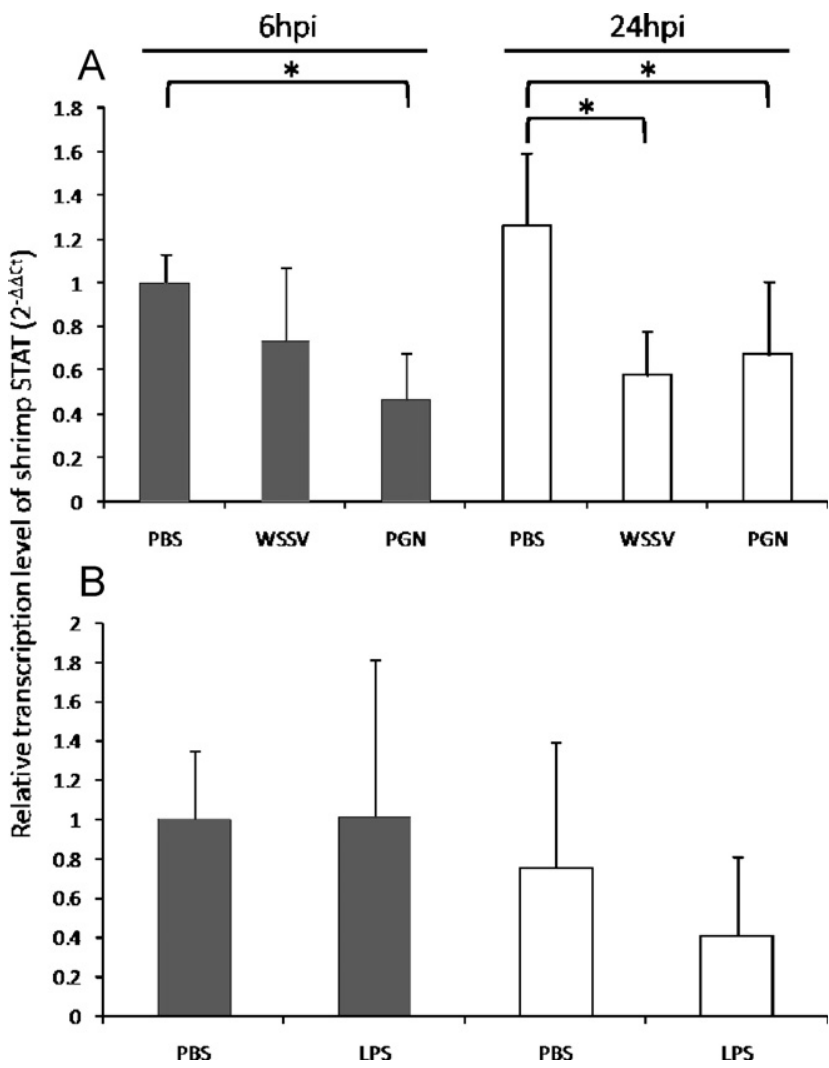

Figure 3 mRNA levels of shrimp STAT after two separate challenge experiments with immune stimulants (A) WSSV and PGN, (B) LPS. Data are the normalized $2^{-\Delta \Delta C t}$ values relative to the PBS-injected shrimps at $6 \mathrm{hpi}$, which has been arbitrarily set to 1. Significantly changed STAT transcription levels $(P<0.05)$ are indicated with an asterisk. Each bar represents mean \pm SD from four to six shrimps.

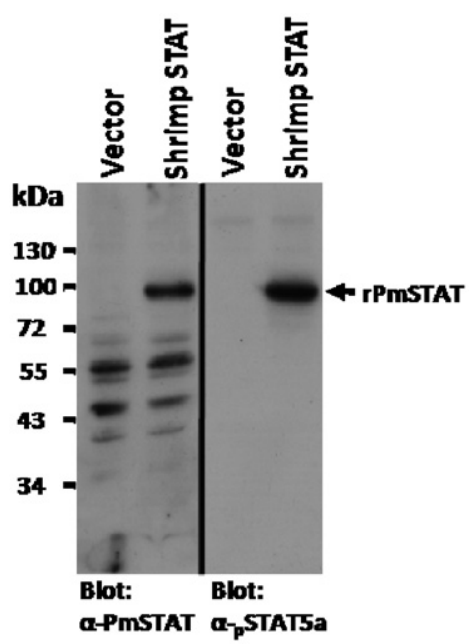

Figure 4 Western blot analysis showing recognition of rPmSTAT by $\alpha$-p STAT5a. Cell lysates were harvested from SF-9 cells transfected with either null vector (lanes 1 and 3 ) or the PmSTAT expression vector, pDhsp/PmSTAT/V5-His (lanes 2 and 4). Western blot analysis of the cell lysates used either anti-shrimp STAT serum (lanes 1 and 2) or $\alpha$-pSTAT5a antibody (lanes 3 and 4). 


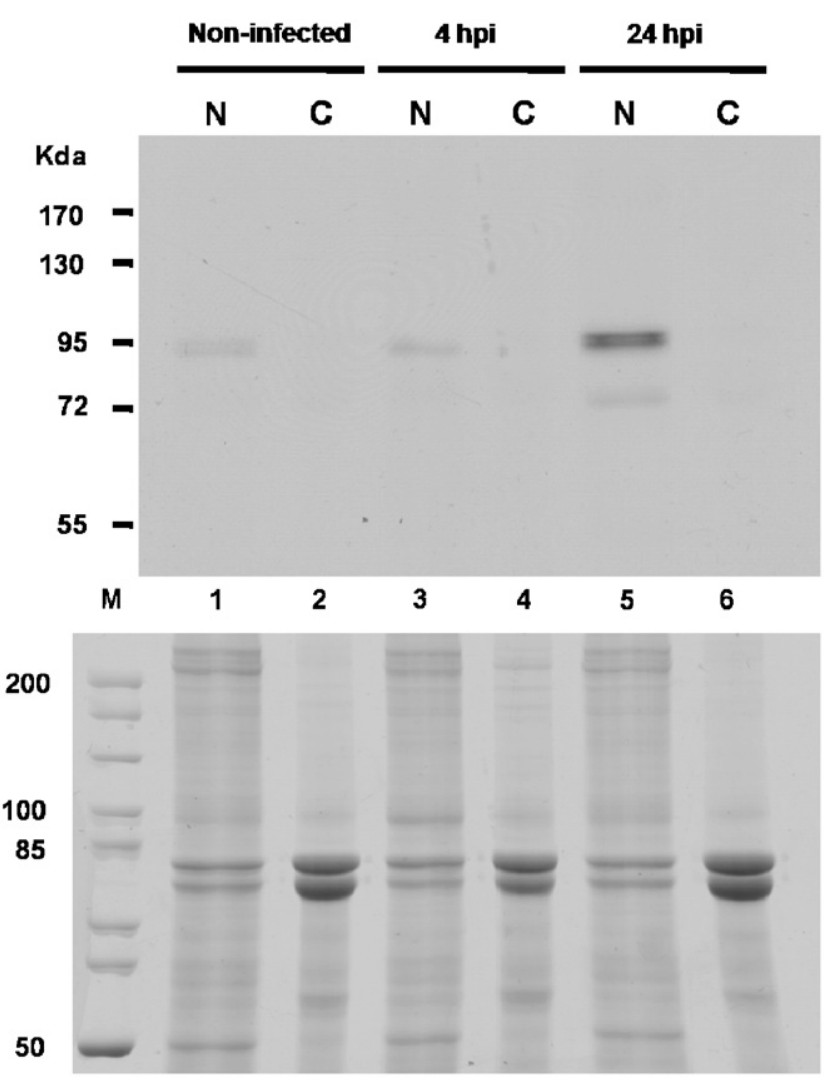

Figure 5 Western blots showing levels of phosphorylated STAT in the LOs of non-infected and WSSV-infected $P$. monodon. Each pair of lanes shows results for the nuclear $(\mathrm{N})$ and the cytoplasmic $(C)$ fractions from a single individual shrimp. The experiment was performed twice, but only one set of results is shown here. Each well was loaded with $15 \mu \mathrm{g}$ total protein. Equal loading of protein in the nuclear and cytoplasmic fractions was confirmed by coomassie blue staining (lower panel).

According to the model postulated by Copeland et al. [26], all of the known STATs can be classified into two groups: the ancient STAT family includes all the insect STATs (AgSTAT, SfSTAT, DmSTAT) as well as human STAT5a, STAT5b and STAT6, while the members of the other family were derived from ancient STAT through duplication events. Our phylogenetic analysis (Figure 2) suggests that shrimp STAT is closely related to the ancient STAT family, and that it is closest to SfSTAT (with 65\% amino acid sequence identity in the conserved central region). We therefore conclude that shrimp STAT belongs to the ancient STAT family.

Three important, highly conserved STAT activation sites were identified in shrimp STAT (Figure 1). Phosphorylation of a single conserved tyrosine residue (around residue 700; Y706 in shrimp STAT) is required for STAT activation and for dimerization, nuclear translocation and DNA binding $[5,6]$. Independently of tyrosine phosphorylation, phosphorylation of the serine residue at the C-terminal of both STAT1 and STAT3 is required for transcription activity and DNA binding activity [27]. This residue was found at S725 in shrimp STAT. Lastly, methylation of Arg31 in STAT1 enhances its DNA binding activity in response to interferon stimulation [28]. This conserved arginine residue was found in the same location in shrimp STAT. The presence of these putatively functional residues in shrimp STAT suggests that similar regulation mechanisms are probably used by shrimp.

In our real-time RT-PCR experiment to investigate the effect of WSSV on STAT transcription levels, we also included two bacterial immune stimulants for comparison (Figure 3). LPS, a cell wall component of Gram-negative bacteria, is a strong elicitor of innate immune responses in many organisms. Its effects include the hemocyte degranulation in horseshoe crab $[29,30]$, the production of antimicrobial peptide in drosophila [31] and the activation of Toll mediated pathways in mammals [32], as well as the activation of the JAK/STAT signaling pathway in mosquitoes [4]. In addition, LPS was also recently shown to affect the mRNA level of several immune effectors in shrimp [33]. Although the mechanisms of these LPS-induced crustacean immune responses are unknown, the fact that STAT transcription levels were barely changed after LPS stimulation (Figure 3), suggests that they are not mediated through the JAK/STAT pathway. However, STAT protein levels would also need to be investigated before the possibility of JAK/ STAT mediation could be ruled out entirely.

Our real-time RT-PCR experiment also used the bacterial immunostimulants PGN, which is a cell wall component from Gram-positive bacteria. PGN is an activator of the Toll signaling pathway in insects and, although there is no previous evidence to suggest its involvement with the JAK/ STAT pathway, we found that it significantly decreased the transcription level of shrimp STAT (Figure 3). It is too early to draw any conclusion from the available data, but we note that crosstalk between the Toll and JAK/STAT pathways has been suggested in drosophila [9].

In a previous study, EMSA results showed that the levels of activated shrimp STAT were higher in WSSV infected shrimp [2]. Surprisingly, however, as Figure 3 shows, STAT transcription levels at $24 \mathrm{hpi}$ were significantly lower in the WSSVinjected shrimps. This observation (i.e. the level of activated STAT was elevated while the transcription level of STAT decreased) was also reported after bacterial infection in mosquito [7] even though, as in the present study, the mechanism still remains unknown. We hypothesize that WSSV acts to reduce, but not completely eliminate, STAT transcription in the host. WSSV would benefit from keeping the STAT transcription above a certain minimum because a minimal STAT transcription level is necessary to drive the expression of viral genes such as ie1; meanwhile it would also benefit the virus to prevent STAT transcription from rising above the basal level in order to avoid eliciting a global antiviral immune response by activating the JAK/STAT pathway.

Given that levels of STAT transcription (Figure 3) and STAT expression moved in opposite direction after WSSV infection, we used two direct analysis methods to reconfirm the earlier finding of elevated levels of activated STAT [2]. Our Western blot analysis was consistent with previous reports [34] in finding that there were already basal levels of activated STAT in non-infected shrimps. These same basal activation levels were still seen at $4 \mathrm{hpi}$ (Figure 5). Given that shrimp STAT is known to bind to the promoter region of the WSSV immediate early gene ie1 [2], these basal levels are presumably sufficient to initiate transcription of this gene. Meanwhile, by $24 \mathrm{hpi}$, levels of activated shrimp STAT had visibly increased (Figure 5), and the timing of this 

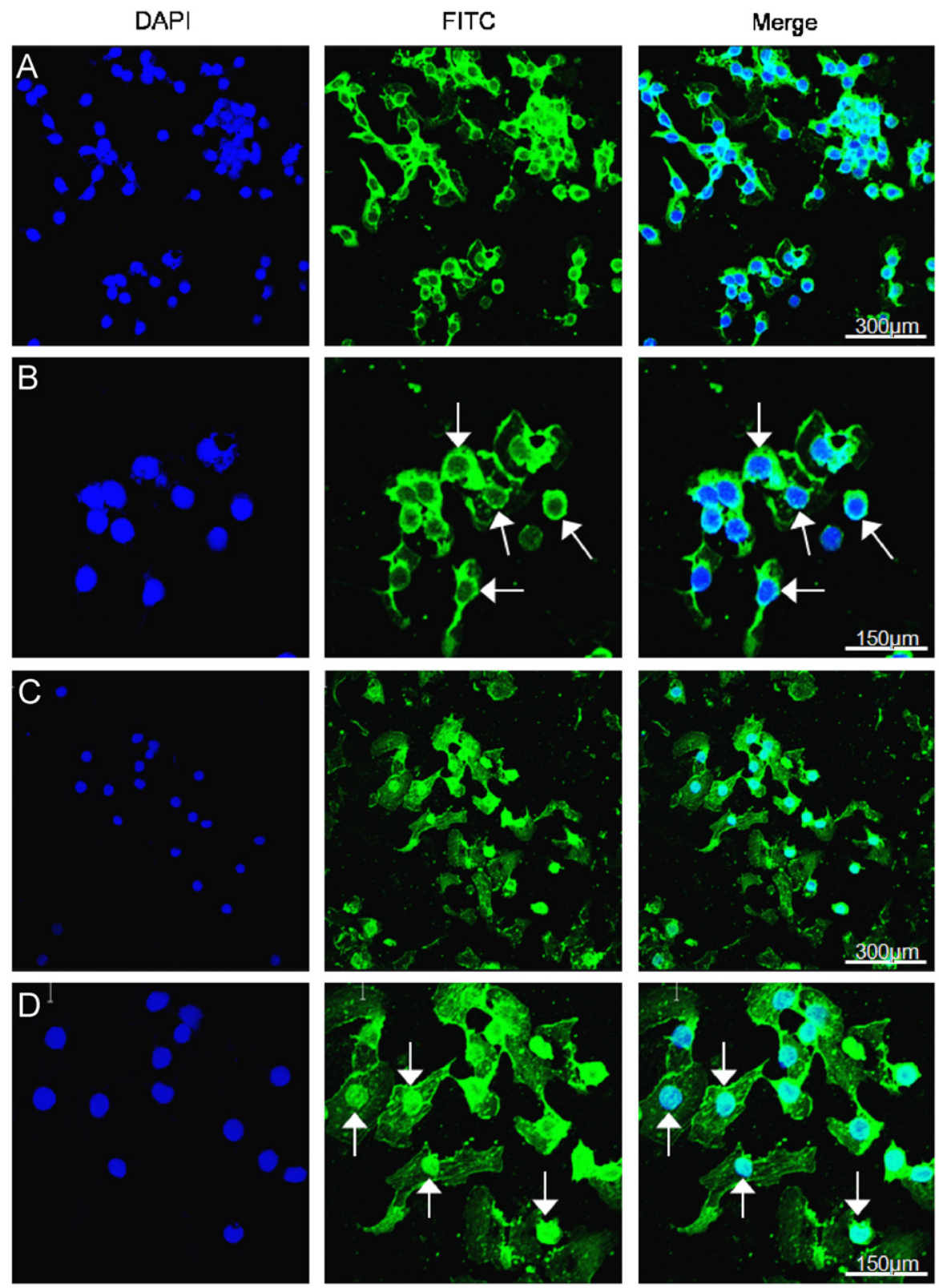

Figure 6 Confocal microscopy showing translocation of shrimp STAT from the cytoplasm to the nucleus after WSSV infection. DAPI was used to counterstain the nuclear DNA and FITC labeling was used to reveal the subcellular location of PmSTAT. Non-infected LO cells with magnification of (A) $200 \times$ and (B) $400 \times$; WSSV-infected LO cells ( $24 \mathrm{hpi}$ ) with magnification of (C) $200 \times$ and (D) $400 \times$. Nuclei are indicated by the arrows.

increase is approximately co-incident with a previous finding that the WSSV ie 1 gene reaches maximal expression at $18 \mathrm{hpi}$ [35]. The activation of shrimp STAT was further confirmed by the immunostaining assay (Figure 6), which showed that after WSSV infection, shrimp STAT subsequently translocated into the nucleus. Using the same approach, a similar nuclear translocation of AgSTAT has also been reported in the mosquito after bacterial infection [7].

\section{Acknowledgments}

We would like to express our gratitude to all members of the Crustacean Virology Laboratory, especially to those who could not be included as authors, but who still have contributed to this work in the past few years. Most importantly, we are indebted to Paul Barlow for his helpful criticism. This investigation was supported financially by the Council of Agriculture's National Science and Technology Program [95 AS-13.4.1-AQ-B1 (1), 95 AS-6.1.6-FA-F1 (z)-(3)].

\section{References}

[1] Takaoka A, Yanai H. Interferon signalling network in innate defence. Cell Microbiol 2006;8:907-22.

[2] Liu WJ, Chang YS, Wang AH, Kou GH, Lo CF. White spot syndrome virus annexes a shrimp STAT to enhance expression of the immediate-early gene ie1. J Virol 2007;81:1461-71. 
[3] Dostert C, Jouanguy E, Irving P, Troxler L, Galiana-Arnoux D, Hetru C, et al. The JAK-STAT signaling pathway is required but not sufficient for the antiviral response of drosophila. Nat Immunol 2005;6:946-53.

[4] Lin CC, Chou CM, Hsu YL, Lien JC, Wang YM, Chen ST, et al. Characterization of two mosquito STATs, AaSTAT and CtSTAT: differential regulation of tyrosine phosphorylation and DNA binding activity by lipopolysaccharide treatment and by Japanese encephalitis virus infection. J Biol Chem 2004;279: 3308-17.

[5] Levy DE, Darnell Jr. JE. Stats: transcriptional control and biological impact. Nat Rev Mol Cell Biol 2002;3:651-62.

[6] Shuai K, Liu B. Regulation of JAK-STAT signalling in the immune system. Nat Rev Immunol 2003;3:900-11.

[7] Barillas-Mury C, Han YS, Seeley D, Kafatos FC. Anopheles gambiae Ag-STAT, a new insect member of the STAT family, is activated in response to bacterial infection. EMBO J 1999;18: 959-67.

[8] Agaisse H, Petersen U-M, Boutros M, Mathey-Prevot B, Perrimon N. Signaling role of hemocytes in Drosophila JAK/ STAT-dependent response to septic injury. Dev Cell 2003;5: 441-50.

[9] Lagueux M, Perrodou E, Levashina EA, Capovilla M, Hoffmann JA. Constitutive expression of a complement-like protein in Toll and JAK gain-of-function mutants of Drosophila. Proc Natl Acad Sci USA 2000;97:11427-32.

[10] Agaisse $H$, Perrimon N. The roles of JAK/STAT signaling in Drosophila immune responses. Immunol Rev 2004;198:72-82.

[11] Didcock L, Young DF, Goodbourn S, Randall RE. The V protein of simian virus 5 inhibits interferon signalling by targeting STAT1 for proteasome-mediated degradation. J Virol 1999;73: 9928-33.

[12] Miller DM, Rahill BM, Boss JM, Lairmore MD, Durbin JE, Waldman JW, et al. Human cytomegalovirus inhibits major histocompatibility complex class II expression by disruption of the Jak/Stat pathway. J Exp Med 1998;187:675-83.

[13] Abendroth A, Slobedman B, Lee E, Mellins E, Wallace M, Arvin AM. Modulation of major histocompatibility class II protein expression by varicella-zoster virus. J Virol 2000;74: 1900-7.

[14] He Y, Katze MG. To interfere and to anti-interfere: the interplay between hepatitis C virus and interferon. Viral Immunol 2002;15:95-119.

[15] Tsai JM, Wang HC, Leu JH, Hsiao HH, Wang AH, Kou GH, et al. Genomic and proteomic analysis of thirty-nine structural proteins of shrimp white spot syndrome virus. J Virol 2004;78: $11360-70$

[16] Livak KJ, Schmittgen TD. Analysis of relative gene expression data using real-time quantitative PCR and the $2_{\mathrm{T}}^{-\Delta \Delta C}$ method. Methods 2001;25:402-8.

[17] Wang CH, Yang HN, Tang CY, Lu CH, Kou GH, Lo CF. Ultrastructure of white spot syndrome virus development in primary lymphoid organ cell cultures. Dis Aquat Organ 2000;41: 91-104.

[18] Azam M, Lee C, Strehlow I, Schindler C. Functionally distinct isoforms of STAT5 are generated by protein processing. Immunity 1997;6:691-701.
[19] Caldenhoven E, van Dijk TB, Solari R, Armstrong J, Raaijmakers JA, Lammers JW, et al. STAT3 $\beta$, a splice variant of transcription factor STAT3, is a dominant negative regulator of transcription. J Biol Chem 1996;271:13221-7.

[20] Schaefer TS, Sanders LK, Park OK, Nathans D. Functional differences between Stat3alpha and Stat3beta. Mol Cell Biol 1997; 17:5307-16.

[21] Hou XS, Melnick MB, Perrimon N. Marelle acts downstream of the Drosophila HOP/JAK kinase and encodes a protein similar to the mammalian STATs. Cell 1996;84:411-9.

[22] Yan R, Small S, Desplan C, Dearolf CR, Darnell Jr. JE. Identification of a Stat gene that functions in Drosophila development. Cell 1996;84:421-30.

[23] Arbouzova NI, Zeidler MP. JAK/STAT signalling in Drosophila: insights into conserved regulatory and cellular functions. Development 2006;133:2605-16.

[24] Christophides GK, Zdobnov E, Barillas-Mury C, Birney E, Blandin $\mathrm{S}$, Blass $\mathrm{C}$, et al. Immunity-related genes and gene families in Anopheles gambiae. Science 2002;298:159-65.

[25] Zdobnov EM, von Mering C, Letunic I, Torrents D, Suyama M, Copley RR, et al. Comparative genome and proteome analysis of Anopheles gambiae and Drosophila melanogaster. Science 2002;298:149-59.

[26] Copeland NG, Gilbert DJ, Schindler C, Zhong Z, Wen Z, Darnell $\mathrm{JE}$, et al. Distribution of the mammalian Stat gene family in mouse chromosomes. Genomics 1995;29:225-8.

[27] Decker T, Kovarik P. Serine phosphorylation of STATs. Oncogene 2000;19:2628-37.

[28] Mowen KA, Tang J, Zhu W, Schurter BT, Shuai K, Herschman HR, et al. Arginine methylation of STAT1 modulates IFN $\alpha / \beta$-induced transcription. Cell 2001;104:731-41.

[29] Iwanaga S, Kawabata S-I, Muta T. New types of clotting factors and defense molecules found in horseshoe crab hemolymph: their structures and functions. J Biochem (Tokyo) 1998;123:1-15.

[30] Kurata S, Ariki S, Kawabata S. Recognition of pathogens and activation of immune responses in Drosophila and horseshoe crab innate immunity. Immunobiology 2006;211:237-49.

[31] Kim YS, Ryu JH, Han SJ, Choi KH, Nam KB, Jang IH, et al. Gramnegative bacteria-binding protein, a pattern recognition receptor for lipopolysaccharide and beta-1,3-glucan that mediates the signaling for the induction of innate immune genes in Drosophila melanogaster cells. J Biol Chem 2000;275: 32721-7.

[32] Heumann D, Roger T. Initial responses to endotoxins and Gramnegative bacteria. Clin Chim Acta 2002;323:59-72.

[33] Okumura T. Effects of lipopolysaccharide on gene expression of antimicrobial peptides (penaeidins and crustin), serine proteinase and prophenoloxidase in haemocytes of the Pacific white shrimp, Litopenaeus vannamei. Fish Shellfish Immunol 2007; 22:68-76.

[34] Vinkemeier U. Getting the message across, STAT! Design principles of a molecular signaling circuit. J Cell Biol 2004;167: 197-201.

[35] Liu WJ, Chang YS, Wang CH, Kou GH, Lo CF. Microarray and RT-PCR screening for white spot syndrome virus immediateearly genes in cycloheximide-treated shrimp. Virology 2005; 334:327-41. 